\title{
Developing role of HPV in cervical cancer prevention
}

In this Clinical Review by H Kitchener and colleagues, the upper graph in figure 4 should have indicated cervical cancer from the age of 15-19 years only, rather than from age 0-4 years (BMJ 2013;347:f4781, doi:10.1136/bmj.f4781). The corrected version of the figure can be found here.

\section{Cite this as: $B M J$ 2013;347:f5207}

๑ BMJ Publishing Group Ltd 2013 
Figure
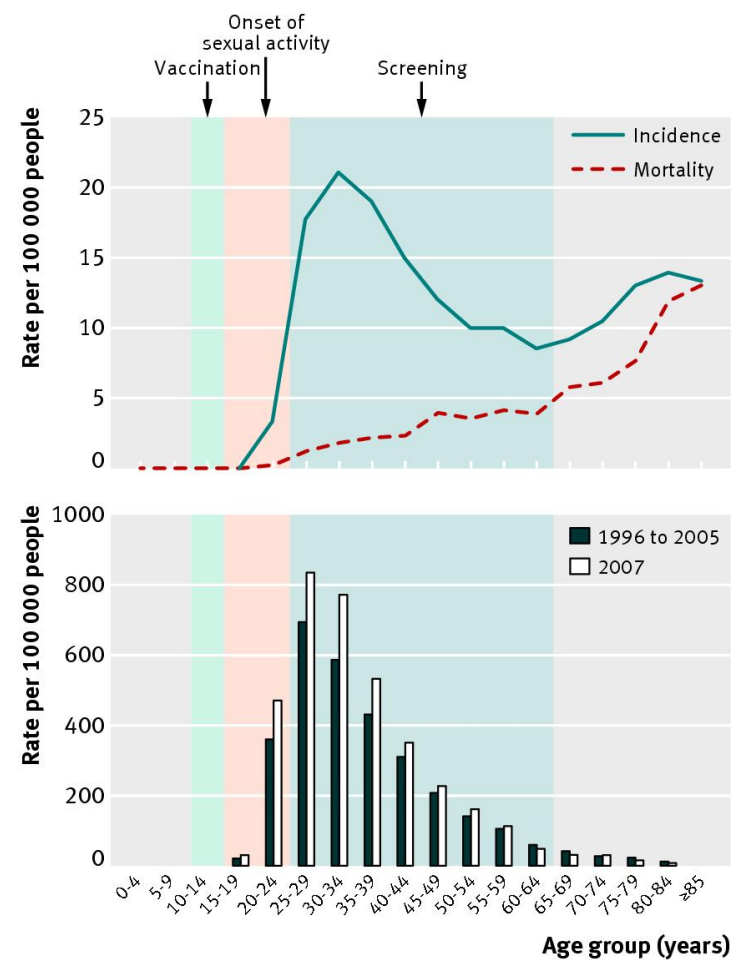